\title{
A conquista de direitos para os nascidos com síndrome da talidomida no Brasil
}

\section{The conquest of rights for born with thalidomide syndrome in Brazil}

\section{Francieli Lunelli Santos*}

Resumo: A síndrome da talidomida afetou o desenvolvimento de crianças brasileiras em fins da década de 1950 e posteriormente. A talidomida era vendida como antiemético e sonífero. Se consumida no período inicial da gestação provocava embriopatias diversas. Milhares de crianças em 46 países nasceram com ausência ou encurtamento dos membros superiores e/ou inferiores. Seus fabricantes não se responsabilizaram pelos efeitos colaterais e as crianças cresceram sob a proteção de seus pais e familiares, sem qualquer direito ou assistência devido a sua condição, por parte do Estado. Com o objetivo de compreender o processo de luta por direitos para as crianças com síndrome, nascidas entre 1959 a 1964, através de pesquisa documental, este artigo analisa o processo de judicialização e posterior construção de legislação em termos de direitos para esse grupo social. A luta por direitos foi morosa, chegando até a idade adulta dos sujeitos a que esta pesquisa se refere.

Palavras-chave: Síndrome da talidomida. Conquista de direitos. Deficiência.

Abstract: The thalidomide syndrome affected the development of brazilian children in the late 1950 s and beyond. Thalidomide was sold as an antiemetic and a sleeping pill. If consumed in the initial period of pregnancy, it caused different embryopathies. Thousands of children in 46 countries were born with absent or shortened upper and / or lower limbs. Its manufacturers were not responsible for the side effects and the children grew up under the protection of their parents and family, without any right or assistance due to their condition, by the State. In order to understand the process of fighting for rights for children with the syndrome, born between 1959 and 1964, through documentary research, this article analyzes the process of judicialization and subsequent construction of

\footnotetext{
* Doutora em Ciências Sociais Aplicadas. Mestre em Ciências Sociais Aplicadas (2009). Especialista em História, Arte e Cultura (2006). Licenciada em História (2004) e Sociologia (2018). Professora do Centro Universitário Santa Amélia - UNISECAL, nos cursos de Direito e Serviço Social.
} 
legislation in terms of rights for this social group. The struggle for rights took a long time, reaching the adulthood of the subjects to which this research refers.

Keywords: Thalidomide syndrome. Conquest of rights. Disability.

\section{Introdução}

No Brasil, o caminho para conquistar direitos para pessoas com deficiência, através de políticas de Estado, foi longo, e grande parte da luta foi realizada a partir da década de 1970 (LANNA JUNIOR, 2010), com uma intensa mobilização de movimentos sociais ligados à causa. Nesse fluxo, estão aqueles afetados pela síndrome da talidomida, que lutavam por direitos compensatórios, pelo reconhecimento de sua existência, como também de sua condição. A história da conquista de direitos para as crianças com deficiências causadas por talidomida se dá em vários momentos, com ênfase em dois, considerando os principais atores do processo: primeiro os pais e, posteriormente, já na fase adulta, os próprios sujeitos. Estes tomaram posição frente à luta, o que os tornou protagonistas das próprias demandas, quando o movimento social retomou o ânimo da batalha pelos direitos.

$\mathrm{O}$ arco temporal da pesquisa abrange os anos de 1959 (início da comercialização do medicamento causador da síndrome no país) até 2018 (evento mais recente da conquista de direitos). A pesquisa versa sobre a luta pela conquista e consolidação de direitos daqueles sujeitos definidos como pertencentes à primeira geração da síndrome da talidomida, ou seja, os nascidos entre 1959 e 1964. Foram identificados casos de nascidos com a síndrome posteriores a 1964, inclusive nas últimas décadas.

O fármaco, desenvolvido na Alemanha como anti-histamínico, foi comercializado em diversos países, em fins da década de 1950 como sonífero e antiemético (potencial de alívio de mal-estar próprio do período gestacional, como náuseas e vômitos) (OLIVEIRA et al., 1999). Apurou-se que no Brasil, o

\footnotetext{
${ }^{1}$ O Ministério da Saúde (2014, p. 19-23) apresenta uma divisão temporal, de acordo com o nascimento dos bebês. A primeira geração, nascidos entre 1959 e 1964, desde a introdução no mercado brasileiro até seu "banimento". A segunda geração remonta aos nascidos entre 1966 a 1998, quando houve nova liberação do uso do medicamento para tratamento de sintomas da hanseníase. Verificou-se a existência de uma terceira geração de crianças nascidas entre 2005 a 2010. No intervalo compreendido entre 1998 a 2004 não foram registrados casos, segundo o Ministério da Saúde (2014, p. 22).
} 
medicamento era vendido até mesmo sem receituário médico e possuía preço relativamente baixo, o que facilitava ainda mais o consumo. Três laboratórios, sediados em São Paulo, passaram a fabricar a talidomida sob os nomes Sedalis e Sedalis 10o, pelo Instituto Pinheiros; Slip, produzido pelo Laboratório Lafi; e Sedin, produzido pelo Farmasa. Todos foram fabricados e comercializados a partir de 1958, com exceção do Sedin que entrou no mercado um ano depois.

A droga demonstrou grande potencial comercial: as publicidades veiculadas na mídia impressa (LEANDRO; SANTOS, 2013) garantiam que não havia efeitos colaterais; não causava vício e permitia ainda um sono revigorante.

Esta garantia acabou por ser equivocada. A talidomida atravessou a barreira placentária e com precisão diabólica sabotou os membros em desenvolvimento do feto, assim as crianças nasceram com as mãos ligadas diretamente a seus ombros e pés ligados diretamente a seus quadris e, em alguns casos horríveis, com as duas anomalias. (KNIGHTLEY, 2005, p. $360)$.

A relação entre o consumo da talidomida e as deficiências foram evidenciadas pelos estudos de um pediatra alemão, o Dr. Widukind Lenz, que vieram a público no mês de novembro de 1961, na Inglaterra pela revista The Lancet, dois anos depois do início da comercialização no Brasil. Lenz observou em diversas crianças recém-nascidas esse tipo específico de malformação. A síndrome poderia se manifestar de diversas formas alterando o desenvolvimento fetal. As deficiências variavam entre "[...] graves defeitos visuais, auditivos, da coluna vertebral e, em casos mais raros, do tubo digestivo e problemas cardíacos." (ABPST, 2018). Sua forma mais conhecida era focomelia (ausência ou encurtamento de membros superiores e/ou inferiores com mãos e pés desenvolvidos diretamente no tronco).

Esta pesquisa consiste em uma análise documental com base em jornais publicados na época e disponíveis através da Hemeroteca Digital da Biblioteca Nacional; partes da ação judicial movida pelos pais e responsáveis contra os laboratórios fabricantes no Brasil e União Federal, transcorrida entre 1976 a 1983; documentário Tá faltando alguma coisa (MAXIMINO; TABOADA, 2012), que rememora a história de duas associações brasileiras; e, entrevista com a presidente da Associação Brasileira de Portadores de Síndrome da Talidomida (ABPST), Claudia Marques Maximino. Tais documentos sistematizados e analisados sob a ótica da Análise de Conteúdo (BARDIN, 2011), fizeram emergir 
duas categorias de análise: o processo de luta e conquista de direitos e a responsabilização dos envolvidos. As fontes históricas foram organizadas em perspectiva cronológica e analisadas a partir do aporte teórico dos Disability Studies (BARNES et al., 2002; BARTON, 2008; DINIZ, 2007) bem como escritos de Erving Goffman (1989) e Michel Foucault (2001) sobre estigma e normalidade na relação com deficiência; Axel Honneth (2003), em termos de luta por reconhecimento.

Conforme mencionam Leandro e Santos (2015), a imprensa periódica no Brasil divulgou a relação entre talidomida e as embriopatias a partir de março de 1962, com certo atraso em relação à descoberta de Lenz e sem proibição imediata do consumo do medicamento no país. Entende-se que a mídia atuou tanto na produção de sentidos para a compreensão de eventos inéditos, como foi o caso da iatrogenia por talidomida, quanto atuou como instrumento elucidativo de discursos e perspectivas já presentes na sociedade ${ }^{2}$ sobre deficiências, em especial, as físicas e motoras.

Assim, a mídia impressa produziu inteligibilidade sobre a deficiência na época e, apesar das representações mais fortes e numerosas ressaltarem a associação entre deficiência e monstruosidade (LEANDRO; SANTOS, 2013), essa não foi a única maneira de compreensão do fenômeno encontrada na imprensa. Através da pesquisa construiu-se uma cronologia da talidomida em vários aspectos: a história do medicamento causador de deficiência; espaço de denúncia e contestação dos diversos atores envolvidos; canal de divulgação da luta das pessoas atingidas pela síndrome e meio de divulgação das conquistas e direitos alcançados. Contudo, avalia-se que a imprensa conferiu reduzido destaque a outros aspectos da vida das crianças, como reabilitação, educação, lazer, profissionalização, limitando o papel dos responsáveis ao "ressarcimento" financeiro dos corpos marcados pela talidomida.

As notícias analisadas demonstram que os jornais deram visibilidade à deficiência sob a ótica de exclusão, ao abusar dos termos, ligados à construção das representações quando da eclosão dos eventos. Essas representações

\footnotetext{
2 Benetti (2008) explica que o jornalismo, enquanto meio de circulação e produção de sentidos, utiliza-se do campo de repertórios que o indivíduo possui previamente, de forma a facilitar a compreensão do leitor e a interpretação com base em suas experiências. A inteligibilidade do fenômeno aqui é permeada por conceitos e significados precedentes, estabelecidos na relação concretizada através do texto jornalístico.
} 
contribuíram para perpetuar uma visão negativa sobre a deficiência, visão que, por vezes, ainda é atribuída às pessoas com deficiência, relegando-os a um espaço de segregação que legitima a interdição ou a dependência. Pensa-se que tanto os responsáveis diretos (fabricantes e Estado) como também a imprensa (em especial do segmento jornalístico), ao seu modo, colaboraram de formas diversas para a estigmatização social, nos termos de Goffman (1989). A mídia atribuía ao indivíduo uma identidade deteriorada, reduzindo-o a um ser com funções comprometidas, e ainda torna a pessoa com deficiência um ser humano diminuído. Com o título "80o crianças ameaçadas em São Paulo", há referência, na notícia, à teratogenia por meio do termo "criança-monstro":

Com um saldo de 4.024.980 unidades dos produtos Sedin, Sedális e Slip apreendidos durante uma semana de blitz, o Serviço de Fiscalização do Exercício Profissional encerrou em São Paulo a sua ação de extermínio da droga-maldita. Foram visitadas mais de 5 mil farmácias e dois laboratórios produtores do medicamento que está fazendo nascer crianças-monstros. (TRIBUNA DA IMPRENSA, 16 ago. 1962, p. 5, grifo meu).

A construção de sentidos nos jornais circunscreve a deficiência enquanto dano, de maneira negativa, entendendo-a como tragédia pessoal, de modo que o que antecede o sujeito, no discurso jornalístico, é a ausência de uma parte de seu corpo, e essa ausência demarca a fronteira entre a normalidade e a anormalidade (FOUCAULT, 2001). Essa construção textual, repleta de repertórios para trazer o leitor a compreender tal realidade, é permeada pela legitimação do estigma. Oculta ou explicitamente, fica clara a perspectiva da exclusão quanto à deficiência física, pois o processo de (não) aceitação da condição de deficiência é pautado por uma normalidade imaginária.

Ao longo dos anos, através da forma de divulgação dos fatos referentes à talidomida, se contribuiu para o modelo biomédico da deficiência. Nesse caso, Débora Diniz indica que, em relação às pessoas com deficiência, “[...] a rejeição à lesão é algo tão difundido nas sociedades industrializadas que a separação entre natureza e sociedade não seria facilmente digerida nas negociações políticas em prol dos direitos" (DINIZ, 2007, p. 2). O modelo biomédico tornou a deficiência algo que antecede a pessoa, ou seja, ela passa a ser definida pelas lesões que possui.

De forma a tensionar essa compreensão da deficiência outro paradigma que surge a partir da década de 1970, o modelo social da deficiência (DINIZ, 
2007). Relevante destacar que o modelo social não suplantou o modelo biomédico; pelo contrário, tais modelos permaneceram em disputa por longo período. Nesse mesmo contexto da luta por direitos para pessoas com talidomida, despontam movimentos sociais e acadêmicos contestatórios da vertente biomédica nos Estados Unidos e Reino Unido que deram origem ao modelo social da deficiência (OLIVER, 2008). Paul Abberley (2008) explica que, compreendidas a partir do modelo social, as deficiências são resultado de fatores sociais, econômicos e políticos e não de características naturais ou processos (in)evitáveis. O modelo social permitiu, seja pelo crescente debate acadêmico através dos chamados Disability Studies, seja por sua incorporação aos espaços políticos com a ampliação da visibilidade das demandas de grupos com deficiência, que uma camada considerada até então minoritária passasse a ser notada em muitos outros aspectos. Segundo esse novo entendimento, a deficiência envolve questões políticas e sociais, e deixa de ser considerada apenas experiência pessoal e familiar, entendida como tragédia. (BARNES et al., 2002).

No Brasil, mesmo com a Constituição Federal de 1988 fornecendo garantias legais para um conjunto mais amplo da população, foram necessários mecanismos de pressão a fim de que direitos de pessoas com deficiência fossem colocados em prática. Durante grande parte do período analisado (1959 a 2018), as pessoas com a síndrome da talidomida não contavam com direito algum, tendo em vista a especificidade da origem de sua deficiência e a ausência de proteção por parte do Estado3, para outros sujeitos que não somente as pessoas com deficiência.

A busca pela criação de tais direitos emerge em um contexto ditatorial e de supressão de liberdades, o que implica numa concepção de direitos limitados4.

\footnotetext{
3 Entende-se, com base em Pereira $(2009 ; 2012)$ que, como o Estado não tinha políticas consolidadas para o tratamento das questões sociais, as pessoas com deficiência, e, para além destas, as pessoas com síndrome da talidomida, foram se somando à quantidade já imensa de pessoas sem qualquer assistência por parte do Estado, que não estivessem vinculadas a um sistema contributivo.

4 Um indicador de como o Estado se posicionou sobre a deficiência durante o regime militar foi apontado por Bahia (2009, p. 328), na relação entre censura e deficiência, em uma norma que dizia respeito ao tratamento dessas questões pela mídia: "[...] as emissoras de rádio e televisão são proibidas de apresentarem programas de apelo à caridade ou ao sentimento público, a exibição de pessoas aleijadas ou com doenças incuráveis.”, que despertassem no público qualquer apelo à caridade. De modo semelhante, notícias sobre epidemias de meningite e poliomielite, doenças que poderiam transformar crianças "saudáveis" em crianças com deficiência, eram muitas vezes censuradas na década de 1970, principalmente na sua primeira metade. (BAHIA, 2009).
} 
Assim, num contexto final do regime militar e mais favorável à criação de direitos sociais foi que as pessoas com a síndrome adquiriram direito a uma pensão indenizatória, através da Lei 7.070/82, via ação judicial coletiva, fomentada através da Associação Brasileira de Vítimas da Talidomida (ABVT). Muitas outras vezes as pessoas com a síndrome da talidomida precisariam se articular com vistas a conquistar novos direitos ou garantir que fossem cumpridos pelo Estado.

No Brasil, o primeiro movimento surgiu 12 anos após o início dos eventos, conforme se discorrerá a seguir. Destaca-se que, nos jornais analisados, a voz dos principais sujeitos desse processo foi silenciada. Antes de 1973, não foram encontradas falas tais fossem dos pais ou das próprias crianças e adolescentes com a síndrome. Colin Barnes explica que,

Mesmo onde existem leis adequadas, desafiar a negação de direitos através dos tribunais é dispendioso em termos de recursos e de tempo. Seja em que país for, a esmagadora maioria das pessoas com deficiência raramente tem recursos e tempo. Além disso, a via legal para a igualdade não desafia as estruturas políticas e económicas [sic] das sociedades capitalistas. (BARNES, 2002, p. 89)

Até 1973, no Brasil noticiou-se que "[...] ninguém chegou a procurar como ocorreu em vários países da Europa - uma indenização.” (DIÁRIO DE NOTÍCIAS, 21 ago. 1973, p. 6). Esse foi o ano de surgimento da primeira associação de pais tendo em vista a aberta de uma ação coletiva contra os fabricantes e o estado brasileiro, noticiada nos jornais analisados.

Durante a pesquisa na mídia impressa brasileira foram encontradas notícias sobre indenizações em outros países, inclusive fora da Europa, pleiteadas junto ao laboratório alemão antes de 1968, contudo, foram individuais. Destacam-se algumas delas: "MONTREAL, 12 (AFP) - O pai de uma criança nascida deformada devido à Talidomida, reclama 500.0oo dólares ao Ministro da Saúde da Alemanha Federal”. (JORNAL DO DIA, 3 jan. 1963, p. 3); “Talidomida no banco dos réus: vítima quer indenização - HAMBURGO, 24 (FP) - O primeiro processo iniciado contra os laboratórios 'Gruenenthal', fabricantes do calmante 'Contergan', à base de Talidomida, foi realizado ontem na Sala Civil do Tribunal de Hamburgo. O processo, que durou apenas cinco minutos, foi iniciado pelo operário Guenther Sempf, o qual pediu àqueles laboratórios o pagamento por danos e perdas, em virtude de sua espôsa [sic] ter dado à luz um menino disforme, porque tomou ‘Contergan' durante sua gravidez.” (ÚLTIMA 
HORA, 24 jan. 1963, p. 6); "Suecos contra talidomida - ESTOCOLMO (Reuters DC) A Associação Sueca de Vítimas da Talidomida iniciou ação contra um grande laboratório, exigindo indenização de 500 mil coroas em nome de um menino de quatro anos, que nasceu sem braços e sem pernas." (DIÁRIO CARIOCA, 20 set. 1965, p. 1);; "Talidomida - Os pais de 28 bebês vítimas da Talidomida (a droga responsável pelo nascimento de crianças deformadas) moveram ação judicial contra o Ministério da Saúde do Japão e duas firmas japonesas de produtos farmacêuticos, reclamando uma indenização global que atinge cêrca [sic] de 800 mil dólares." (ÚLTIMA HORA, 15 nov. 1965, p. 5).

\title{
O surgimento da Associação Brasileira de Vítimas da Talidomida (ABVT) e a judicialização da deficiência pela síndrome
}

Movimentos sociais de naturezas e demandas diversas surgiram vertiginosamente no Brasil durante a década de 1970. Verificou-se que houve a organização de sujeitos de forma a “[...] expressar suas demandas” (GOHN, 2011, p. 335) por estratégias variadas. No caso específico de movimentos de pessoas com deficiências, Symone M. M. Bonfim adverte que

\begin{abstract}
As entidades representativas passaram a reivindicar uma efetiva participação social e equiparação de oportunidades, com respeito às diferenças individuais e a disponibilização de ferramentas que possibilitem alcançar o ideal da igualdade social. Os conceitos que sustentam o paradigma da inclusão social - vida independente, autonomia, empowerment - norteiam as ações dos grupos que os representam, e funcionam como alavancas para a luta que diuturnamente travam para alcançar [...] reconhecimento social. (2010, p. 62).
\end{abstract}

Nos jornais, as primeiras menções à luta por direitos aparecem a partir de 1973, por ocasião da divulgação de informações sobre a fundação da primeira associação brasileira de amparo às pessoas com a síndrome. A entidade surgiu em Porto Alegre, tendo como liderança a mãe de uma das crianças, Nelci Lima de Oliveira. O jornal carioca Diário de Notícias publicou matéria a respeito, indicando que, na ocasião de sua inauguração, vinte pais integravam a ABVT (DIÁRIO DE NOTÍCIAS, 3 out. 1973).

A mídia impressa foi o canal de comunicação encontrado pela ABVT como forma de contatar os pais e responsáveis pelas crianças nascidas com a 
síndrome em diversas localidades do Brasil; já que por parte do Estado não se divulgavam ou simplesmente inexistiam registros dos nascimentos, e os procedimentos para contabilizar as pessoas com deficiência por talidomida no território nacional eram ineficientes. Nesse momento, no início da década de 1970, vale destacar que o governo brasileiro emudeceu diante da mobilização das famílias. O Serviço Nacional de Fiscalização da Medicina e da Farmácia (SNFMF),

[...] órgão do Ministério de Saúde, diz que "não pode dar qualquer informação oficial" a respeito do primeiro processo brasileiro [da talidomida]. Mas os pais das vítimas continuam esperando que o Governo facilite a luta pela conquista das indenizações, fazendo inclusive um levantamento oficial do número das vítimas, já que os médicos, considerando-se culpados por receitarem medicamentos à base de talidomida, negam qualquer tipo de informação. (DIÁRIO DE NOTÍCIAS, 29 ago. 1973, p. 6).

Por ocasião do debate acerca da responsabilização da classe médica sobre a talidomida, na Associação Médica da Guanabara, o secretário do órgão, Dr. Mário Victor Assis Pacheco, defendeu os médicos que receitaram o fármaco, argumentando que estes "agiram de boa fé", pois confiaram na honestidade dos laboratórios, de forma que a classe médica não poderia ser responsabilizada pelos efeitos adversos da droga. A publicação dizia ainda que a referida Associação Médica havia solicitado aos médicos que se manifestassem sobre o conhecimento de casos de focomelia em virtude do uso gestacional da talidomida: "Até o dia de ontem, nenhum médico do Rio de Janeiro se pronunciou sobre o assunto." (DIÁRIO DE NOTÍCIAS, 29 ago. 1973, p. 2). A classe médica em geral se absteve de avaliar o caso.

Ao seu modo, aos poucos, a imprensa periódica brasileira, mesmo não tendo feito campanha de sensibilização da opinião pública também contribuiu para a articulação política das pessoas com deficiência, na luta por direitos (DE CARLI, 2003). Isso é perceptível no depoimento de uma das mães de pessoa com deficiência por talidomida e fundadora da ABVT na cidade de Campinas, Angelina V. P. Naccarato, ao ressaltar que "a imprensa ajudou muito." (MAXIMINO; TABOADA, 2012). Outra mãe, Myriam Barrio, ainda elucida que

O começo da luta da talidomida em Minas Gerais foi [assim]... nós ficamos conhecendo o movimento do Rio Grande do Sul através da imprensa. A princípio, nós não sabíamos nem como 
começar. Aí entramos em contato com o Sul, que nos deu as diretrizes. Reunimos alguns pais aqui de $\mathrm{BH}$, que conhecíamos, e resolvemos criar uma sucursal [...]. (MAXIMINO; TABOADA, 2012).

Avalia-se que de maneira tímida, a mídia contribuiu para a localização, identificação e comunicação entre as pessoas com a síndrome espalhadas pelo país. Ressalta-se a falta de empenho do governo federal e das autoridades sanitárias em identificar os casos de nascidos com a síndrome da talidomida. A representante da ABVT naquela ocasião, Nelci Lima de Oliveira, lançou um chamado a "[...] todos os pais em situação idêntica para se unirem e lutar pelas indenizações.” (DIÁRIO DE NOTÍCIAS, 29 ago. 1973, p. 6). Alguns jornais passaram a divulgar informações de utilidade pública dos "familiares da talidomida”. E depois das publicações de chamamento aos pais pela ABVT, o governo do Rio Grande do Sul se manifestou em favor das famílias das crianças com a síndrome. A Secretaria de Saúde gaúcha se prontificou a realizar um "[...] novo levantamento das vítimas" (DIÁRIO DE NOTÍCIAS, 21 ago. 1973, p. 6), pois havia sido acusada de ser errônea a quantidade de casos divulgados pela própria Secretaria. Havia indicado apenas 10 casos da síndrome, sendo que nenhum deles era de Porto Alegre. Para o mesmo período, a Associação anunciava 20 casos no estado e 29 no restante do país. Assim, pela imprensa, recomendava que os pais entrassem em contato com a ABVT (DIÁRIO DE NOTÍCIAS, 21 ago. 1973).

Segundo a mídia impressa, de forma a auxiliar tal processo, o Dr. Moacyr Scliar, médico da Saúde Pública do estado, liderou a junta médica, composta também por um pediatra e um obstetra, para atuar como “[...] substrato técnico a estas pessoas.” (DIÁRIO DE NOTÍCIAS, 29 ago. 1973, p. 2). Tal comissão deveria "[...] submeter a exame clínico e radiológico as crianças prejudicadas, elaborando os competentes laudos periciais. Em consequência, foram examinadas cerca de 57 crianças”. (PROCESSO 5.678/76, p. 30).

A partir da organização da associação no Rio Grande de Sul houve um despertar de iniciativas semelhantes no estado de São Paulo:

Angelina P. Nacaratto, [...] é mãe de um garoto que sofreu as influências da Talidomida. [...] Suportou e superou o problema, até que um dia leu em O CRUZEIRO uma reportagem sobre a Associação Brasileira de Pais e Amigos das Vítimas da Talidomida. Não conhecia nenhuma outra similar em São Paulo, mas sabia que, só em Campinas, eram nove os casos análogos. Procurou entrar em contato com todos e, pergunta aqui, informa 
ali, conseguir reunir em Campinas 22 famílias de diversas cidades de São Paulo para organizar um movimento nesse Estado. (O CRUZEIRO, jan. 1975, p. 12).

Angelina Naccarato reforça, ainda, no documentário Tá faltando alguma coisa: "Talidomida... o que era a talidomida? Era uma ilustre desconhecida, ninguém sabia..." (MAXIMINO; TABOADA, 2012). O desconhecimento sobre a deficiência causada pelo medicamento ampliou ainda mais as dificuldades em termos de tratamento, busca de auxílio e conquista de direitos. Uma mãe que optou pelo anonimato aparece no mesmo documentário reforçando a falta de informações sobre a relação entre a medicação e as deficiências:

E depois de mais ou menos um ano é que se aventou a notícia da talidomida e que saiu na mídia e que a gente conseguiu ver o nome do remédio que me foi receitado e nós soubemos a causa. 50 anos atrás ninguém nunca tinha ouvido dizer que uma medicação interferisse numa gestação... eu não tinha essa preocupação... (MAXIMINO; TABOADA, 2012).

Jacobus Van Dijk, pai de uma criança da primeira geração, explica que

Um ano e meio depois, eu e minha esposa "ficava" numa tremenda dúvida: o que será? Eu nunca tive nenhuma doença venérea, ela também não. Nada na família. Os próprios médicos não sabiam [...]. Até que um dia chegou à minha mão [a revista] Time: nasceram bastante [crianças] ou muitas foram entregues a instituições, ou os pais se divorciaram e deu muitos problemas familiares. (MAXIMINO; TABOADA, 2012).

Ainda de acordo com Naccarato, a necessidade de mobilização era urgente:

Nós precisamos fazer alguma coisa pelos nossos filhos, porque um dia eles nos perguntarão: "Por que eu sou assim?" [...]. Então precisamos ver... vamos nos unir, vamos fazer alguma coisa. No Rio Grande do Sul, um grupo também reuniu-se e nós nos reunimos a ele. A nossa luta começou já na justiça. (MAXIMINO; TABOADA, 2012, grifo meu).

Myriam D. A. Barrio, rememora que

[...] era uma época muito difícil porque nós lutamos contra... era ainda a Ditadura e [contra uma] multinacional... assim começou a nossa Associação... e nós começamos aqui através da imprensa, solicitando aparecimento, cadastrando as vítimas com problemas financeiros porque a Associação só era ajudada pelos pais. (MAXIMINO; TABOADA, 2012). 
Mais pais de crianças com a síndrome foram identificados e ingressaram na Associação, com vistas à inclusão na ação judicial. Conforme depoimento de uma outra mãe:

O primeiro contato foi com a dona Angelina Naccarato de Campinas, que fez uma procura de vítimas da talidomida e fundou essa Associação. A gente ficou vibrando de alegria, porque até então nós éramos ao Deus dará... Imagina... não foram reivindicar nada... a gente não tinha nada... não tinha nada... a quem recorrer? Ao Papa, porque governo, políticos, a Deus... (MAXIMINO; TABOADA, 2012).

\section{E Angelina Naccarato explicou que}

Nós começávamos a atender crianças de outros estados... tínhamos que trazer essas crianças a Campinas para passarem pelos exames médicos na Unicamp. Como trazê-las? A Unicamp ficou incumbida de fazer a avaliação médica e a PUC, psicológica. Nós temos que dar este começo a quem? Às próprias crianças. Mas aí já não eram mais crianças, eram jovens... (MAXIMINO; TABOADA, 2012).

Com 30 anos de atuação, a ABVT continuou promovendo a luta das pessoas com deficiência. A sede da Associação mudou para Belo Horizonte. Já num contexto próximo ao início da ação judicial, a revista $O$ Cruzeiro, publicou matéria intitulada "Vítimas da talidomida", destacando a formação da associação e a importância da identificação de novos casos pelo Brasil. Evoca a reportagem que, as pessoas com a síndrome e seus familiares

Necessitam da união de todos para que se saiba quantos são em todo o Estado de São Paulo - [e] em todo o Brasil. Eles querem que os pais mais arredios apareçam para formar a grande corrente que deixará todos com a certeza de que seu caso não é único. Eles precisam de toda a ajuda oficial do Governo para apoiá-los na luta contra o laboratório alemão que, embora na melhor das intenções, fabricou a droga que os vitimou. [...] Procure integrar-se no movimento liderado em Campinas por Dona Angelina Picolotto Nacaratto. [...] Ajude a formar a Associação Paulista de Pais e Amigos das Vítimas da Talidomida, a exemplo da que já existe no Rio Grande do Sul. Lembre-se de que seu filho não é o único. (O CRUZEIRO, jan. 1975, p. 12)

A matéria procurava encorajar os pais a identificarem-se e procurarem assistência do Estado. A estratégia da Associação parece ter surtido efeito, pois logo foram localizados novos casos pelo país. No processo da talidomida, os dados referentes à quantidade de casos são questionados na peça de acusação, conforme será apresentado adiante. Mesmo sem contar com a apresentação da pesquisa 
sobre a totalidade de casos, os números indicados no processo são muito superiores àqueles suspeitos inicialmente pelo governo do Rio Grande do Sul:

Inobstante esta carência de dados, fala-se, extra-oficialmente, que o número de vítimas da droga, no Brasil, oscila entre 300 a 600 casos. Por outro lado, a "ASSOCIAÇÃO BRASILEIRA DE PAIS E AMIGOS DAS CRIANÇAS VÍTIMAS DA TALIDOMIDA" - possui cadastradas cerca de 190 crianças [...]. (PROCESSO $5.678 / 76$, p. 30).

Além de tentar identificar casos da síndrome através da imprensa, a ABVT também motivou os pais a aderirem à ação indenizatória coletiva. Em fevereiro de 1974, uma nota oficial divulgada pela ABVT veio a público chamar a atenção para a importância de todos os pais de crianças com a síndrome participarem de uma ação conjunta, organizada através da associação. A referida nota fez um apelo "[...] contra a inconveniência de negociações individuais." (PROCESSO 5.678/76, p. 32). Ao que tudo indica, essa tática também teve efeitos positivos. No conteúdo da ação judicial afirma-se que a Associação tinha como presidente, Walkírio Ughini Bertoldo5. Este, além de advogado das famílias, era tio de um dos demandantes no processo, que nasceu com focomelia.

Outras estratégias de mobilização foram utilizadas pela ABVT. Em 1977, o Diário do Paraná fez a seguinte publicação: "Crianças pedem ajuda de Geisel para indenização.” (DIÁRIO DO PARANÁ, 16 out. 1977, p. 2). Dois adolescentes da primeira geração teriam enviado uma carta aberta ao presidente Geisel solicitando sua atenção para o primeiro processo judicial movido no Brasil. Não foram encontradas informações sobre atitudes tomadas pelo presidente a respeito do caso. Ao que parece, o pedido seguiu ignorado pelo Governo Federal. ${ }^{6}$

Nova solicitação de apoio foi remetida em 1978 pelas famílias da ABVT para o candidato à presidência João Baptista de O. Figueiredo. O general havia se comprometido em ajudar na causa. Junto ao deputado Augusto Trein, da Arena

\footnotetext{
5 Ele nasceu em 1930, em Tapejara (RS), e a cegueira foi constatada por volta de um ano de vida, quando contraiu meningite. Graduou-se em Direito pela PUC-RS, em dezembro de 1957. Em 1959, tornou-se procurador geral da prefeitura de Porto Alegre, mesmo contrariamente às expectativas dos demais funcionários. Sobre a trajetória do primeiro advogado cego do país, consultar SELAU; DAMIANI, 2014.

6 Aventa-se que o silenciamento do governo federal sobre o tema possa ter sido proposital. Importante lembrar que, em 1975, Geisel assinou com a Alemanha o "Acordo Brasil", que tinha como objetivo construir usinas nucleares e tecnologia de produção de combustível à base de urânio. Alemanha era o país de origem da Chemie Grunenthal, detentora da patente do fármaco. A empresa foi isentada de responsabilidade no caso da ação judicial brasileira. Alguns pais conseguiram auxílio individual concedido por uma fundação criada e mantida pela Chemie.
} 
(RS), uma comissão esteve com Figueiredo que demonstrou indignação quanto à situação das pessoas afetadas. Os representantes da Associação lhe entregaram farta documentação: dados sobre a talidomida no mundo e no Brasil, bem como "[...] fotos dos padrões de danos físicos nas crianças, assim como laudos periciais de geneticistas." (DIÁRIO DO PARANÁ, 2 ago. 1978, p. 4).

Por fim, a matéria chamava a atenção para o comportamento do governo brasileiro face aos danos: "O Brasil é o único país do mundo em que as vítimas da Talidomida não receberam qualquer satisfação do Estado ou laboratórios produtores, segundo informou o assessor jurídico da entidade." (DIÁRIO DO PARANÁ, 2 ago. 1978, p. 4). Assim, em 1976 ingressaram com a ação os demandantes, representados pelo escritório de Walkírio. Eram 146 adolescentes, dos quais 82 eram meninos e 64 eram meninas, todos nascidos entre junho de 1956 e janeiro de 19667.

\section{O Processo 5.678/76: teor e sentença}

O processo movido na Justiça Federal do Rio Grande do Sul, iniciado em 1976 e foi concluído em 1983. As partes do Processo 5.678/76 a que se teve acesso dividem-se em: acusação contra os laboratórios e a União, assinada pelo escritório de advocacia de Walkírio; argumentos de defesa de cada uma das três empresas que fabricaram a talidomida no Brasil entre 1959 e 1961; e os argumentos de defesa da União Federal. Além dessas, também a sentença emitida pela Justiça Federal de Primeira Instância, sediada no Rio Grande do Sul, representada pelo juiz Dr. Luiz Dória Furquim. Os laboratórios processados pelos autores eram: Syntex do Brasil S. A., sucessor do Instituto Pinheiros; Laboratório Lafi Ltda; e Farmasa - Laboratório Americano de Farmacoterapia.

Quase um ano depois do encontro com o presidente Figueiredo, a demora no resultado do processo da talidomida no Brasil continuava em pauta:

Cansados de esperar pela decisão judicial, os diretores da Associação Brasileira de Vítimas da Talidomida enviarão telegrama a Brasília solicitando audiência com o presidente João Baptista Figueiredo e com o ministro da Previdência Social, Jair Soares. (DIÁRIO DO PARANÁ, 12 jun. 1979, p. 4).

\footnotetext{
7 Do total, quase 30 dos casos foram excluídos da ação judicial por insuficiência de provas, período diferente daquele em que o fármaco foi produzido e ficou disponível no comércio de balcão (1959 a 1964) e/ou caracterização de deficiências causas por outros fatores que não a talidomida.
} 
De acordo com o advogado dos denunciantes, a insistência em contatar o presidente Figueiredo (empossado em março daquele ano), deu-se porque este "[...] mostrou-se impressionado com o problema e [ficou] disposto a ajudar-nos quando fosse presidente. Agora vamos até ele reforçar nossos pedidos e tentar apressar uma possível interferência sua no caso.” (DIÁRIO DO PARANÁ, 12 jun. 1979, p. 4). A ação já corria há mais de três anos. Walkírio Bertoldo sustentava ainda que "[...] o que a ABVT deseja é um acordo amigável que venha em benefício de 146 crianças de vários estados brasileiros vítimas da talidomida" (DIÁRIO DO PARANÁ, 12 jun. 1979, p. 4, grifo meu), como solução mais célere e abrangente para estabelecer um fim ao conflito. Primava-se pela urgência do resultado, levando em conta a falta de assistência aos atingidos pelo medicamento.

Anos mais tarde, o resultado do processo teve alguma repercussão nos veículos de imprensa brasileiros. Um dos jornais que abriu certo espaço para publicar as especulações sobre a sentença foi o jornal carioca Última Hora:

PORTO ALEGRE - O acordo a ser homologado na Justiça Federal, entre as vítimas da talidomida [...] e os três laboratórios responsáveis pela fabricação do remédio, além do Governo, que concederá pensão vitalícia, acontecerá na próxima quarta-feira. [...]. Os laudos elaborados pelos médicos geneticistas indicados pelo juiz da $5^{\mathrm{a}}$ Vara Federal de Porto Alegre e pelas partes em questão estão em fase de conclusão. Por isso, o acordo está previsto para dentro de uma semana - explicou Walkírio, salientando que nem todos que ajuizaram a ação contra os laboratórios e a União receberão a indenização e a pensão. $\mathrm{O}$ advogado das vítimas explicou que os médicos examinam cada caso individualmente, com o objetivo de constatar se a pessoa é realmente vítima da talidomida e o grau do dano. Walkírio não tem previsão de quantas pessoas serão beneficiadas com o acordo, mas calcula que o número não será inferior a 150, em todo o País. (ÚLTIMA HORA, 17 fev. 1983, p. 10).

Em 5 de abril de 1983, a Justiça Federal homologou o acordo que previa pagamento de indenização por parte dos laboratórios e pensão vitalícia, a ser paga pela União Federal seguindo os critérios de natureza dos danos, déficit laboral e tipificação de dependência,

[...] tudo em conformidade com as especificações e respectivas gradações determinadas nos laudos médico-genéticos, segundo a soma individual de pontos que vier a ser obtida na escala abaixo indicada, sendo atribuído a cada ponto, o valor correspondente a $1 / 4$ (um quarto) do maior salário mínimo vigente no País, reajustável a cada ano posterior à data do início 
de vigência da pensão, conforme o índice de variação nominal das Obrigações Reajustáveis do Tesouro Nacional. (PROCESSO $5.678 / 76$, fl. 3935).

Assim, o sistema de cálculo das pensões obedeceu ao critério de mapeamento do corpo com deficiência, estabelecendo como 16 o número máximo de pontos para cada um dos demandantes e valor máximo de pensão de quatro salários mínimos, critérios esses que estavam regulamentados na Lei n. 7.070/82, conforme percebe-se através do Quadro 1:

Quadro 1 - Escala de pontuação por danos

\begin{tabular}{|c|c|c|}
\hline \multirow{3}{*}{ 1. Físico } & Discreto & 1 ponto \\
\hline & Moderado & $\begin{array}{c}2 \\
\text { pontos }\end{array}$ \\
\hline & Severo & $\begin{array}{c}3 \\
\text { pontos }\end{array}$ \\
\hline \multirow{3}{*}{ 2. Estético } & Discreto & 1 ponto \\
\hline & Moderado & $\begin{array}{c}2 \\
\text { pontos }\end{array}$ \\
\hline & Severo & $\begin{array}{c}3 \\
\text { pontos }\end{array}$ \\
\hline \multirow[t]{2}{*}{ 3. Déficit Laborativo } & Parcial & 1 ponto \\
\hline & Total & $\begin{array}{c}2 \\
\text { pontos }\end{array}$ \\
\hline \multirow{2}{*}{$\begin{array}{c}\text { 4. Tipo de } \\
\text { Dependência } \\
\text { 4.1 Higiene }\end{array}$} & Parcial & 1 ponto \\
\hline & Total & $\begin{array}{c}2 \\
\text { pontos }\end{array}$ \\
\hline \multirow[b]{2}{*}{ 4.2 Alimentação } & Parcial & 1 ponto \\
\hline & Total & $\begin{array}{c}2 \\
\text { pontos }\end{array}$ \\
\hline \multirow[b]{2}{*}{ 4.3 Deambulação } & Parcial & 1 ponto \\
\hline & Total & $\begin{array}{c}2 \\
\text { pontos }\end{array}$ \\
\hline \multirow[b]{2}{*}{ 4.4 Vestuário } & Parcial & 1 ponto \\
\hline & Total & $\begin{array}{c}2 \\
\text { pontos }\end{array}$ \\
\hline
\end{tabular}

FONTE: Processo 5.678/76, fls. 3935-36 
As perícias médicas foram realizadas por médicos indicados pelo Poder Judiciário. Eram eles, Dr. Francisco M. Salzano; Dra. Márcia Schmidt; Dr. Pedro H. Saldanha e Dr. Cláudio C. Ortega. Segundo seu relatório (anexo ao processo), foram examinados documentos referentes a 252 demandantes, "[...] todos portadores de graves defeitos físicos." (PROCESSO 5.678/76, fl. 3910), porém, nem todos causados por talidomida. O processo pericial foi minuciosamente explicado nas páginas subsequentes. Realizado em duas fases (na primeira, exames dos autores primitivos, os 146 primeiros demandantes; e, na segunda, os 106 que foram inseridos no decorrer da ação). Os dados analisados pelos referidos médicos eram matemáticos seguindo os critérios do modelo biomédico da deficiência.

Concluída a sentença através do acordo, os laboratórios Sintex e Lafi comprometeram-se em depositar em juízo a quantia "[...] equivalente a 55.000 (cinquenta e cinco mil) Obrigações Reajustáveis do Tesouro Nacional (ORTNs).” (PROCESSO 5.678/76, fl. 3937), a ser dividida igualmente entre os 121 demandantes da ação. Os valores foram estimados em Cr\$ 500 mil com relação a grau mínimo, e Cr\$ 2,5 milhões quando atingisse o grau máximo, ou seja, quando causasse o comprometimento físico dos membros superiores e inferiores.

Embora as indenizações e as pensões vitalícias incidissem sobre "problemas emergentes", como descrito no processo, existem outros aspectos da vida que não foram levados em conta. Walkírio destacou no processo um aspecto fundamental na vida das pessoas com deficiência por talidomida:

[...] o maior desafio, a batalha suprema desta guerra contra a talidomida consiste, precisamente, na luta pela reabilitação, pelo bem-estar e pela felicidade de todas as crianças, tão impiedosamente marcadas pelo tranqüilizante [sic] malévolo, de tal sorte que as mesmas se tornem cidadãos úteis a si, à pátria e à coletividade. (PROCESSO 5.678/76, p. 21).

Destaca-se que tais resultados foram obtidos mediante intensa participação das famílias que se associaram à ABVT para iniciar a ação coletiva, como forma de construção dos direitos para seus filhos que tinham a síndrome. Nesse sentido, evidencia-se essa percepção sobre o Processo 5.678/76, que se constitui como uma das primeiras manifestações da luta pelos direitos para as pessoas com a síndrome da talidomida. Com o passar dos anos, o valor da pensão tornou-se ínfimo. As crianças e adolescentes, tornaram-se adultos e iniciaram um 
novo processo de luta: pela correção monetária do valor da pensão entre outros direitos.

\section{Novos sujeitos por mais direitos: a criação da Associação Brasileira de Portadores de Síndrome da Talidomida (ABPST)}

A Lei n. 7.070/82 foi aprovada no final do contexto de ditadura, e seus impactos não tão benéficos foram mais evidenciados ao longo da década: 0 recebimento da pensão não foi imediato e o seu valor tornou-se ínfimo diante da crise econômica do período. A Figura 1 demonstra a variação significante no aumento da inflação. Esses dados ilustram a diminuição do poder aquisitivo da população brasileira e reforçam que a pensão foi perdendo a capacidade de garantir o provimento das pessoas com a síndrome da talidomida.

Figura 1 - Gráfico da inflação brasileira - variação (\%) - 1970 a 1989

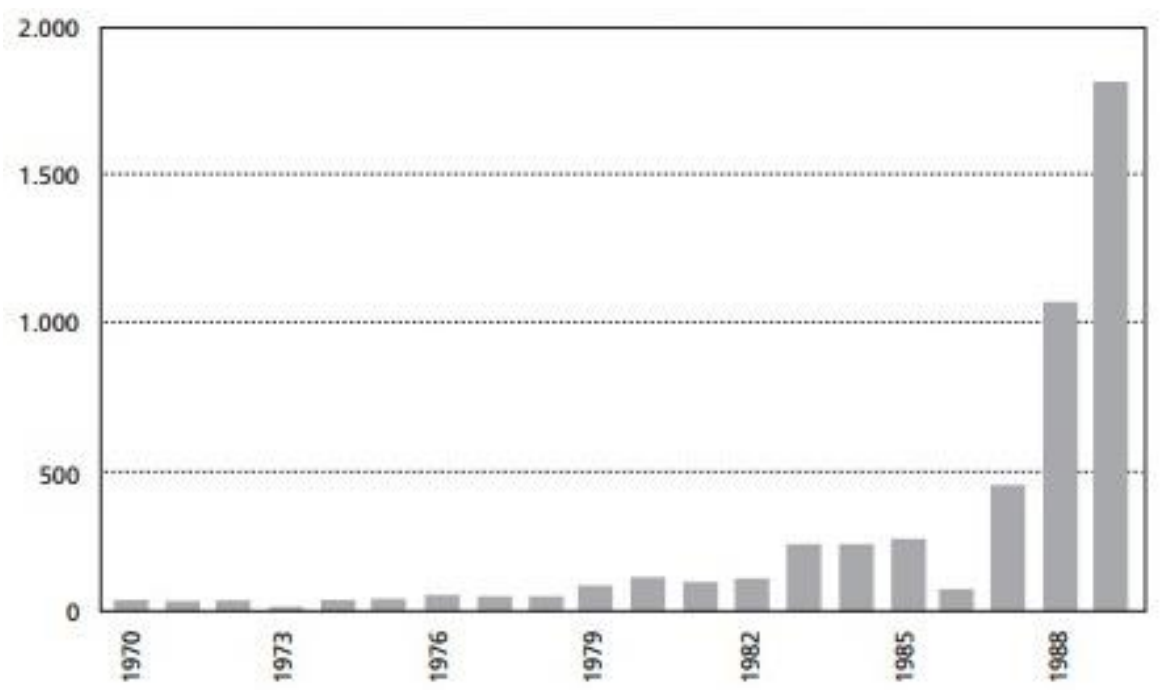

FONTE: MUNHOZ, D. G. Inflação brasileira: os ensinamentos desde a crise dos anos 30.

Economia Contemporânea, n. 1, jan./jun. 1997. p. 65 .

As evidências apontadas, como o valor diminuto da pensão e a complexidade da realidade econômica do país, decorrente da elevação inflacionária $^{8}$, transformaram antigas conquistas em pontos de articulação de

\footnotetext{
${ }^{8}$ Pereira (2010) destaca que, para esse momento histórico, “[...] os ataques conservadores contra os avanços constitucionais de cunho social se fortaleceram com a entrada no país da ideologia neoliberal, durante o governo Collor [de] Mello (1990). Nesse momento, caminhou-se vigorosamente para o desmonte (e não apenas a contrarreforma [...]) do embrião do Estado de Bem-Estar universalista e equânime desenhado na Constituição" (p. 16). Nesse sentido, as
} 
novas demandas. Entende-se que essas novas demandas dizem respeito aos fatores que foram desconsiderados pela Lei n. 7.070/82 (a defasagem do valor da pensão com o tempo e a ausência da preocupação por parte do Estado com problemas cotidianos da vida das pessoas com síndrome da talidomida, tais como educação, saúde, lazer e inserção no mercado de trabalho), o que acabou por suscitar novas lutas com novas pautas reivindicatórias para os atingidos pela síndrome da talidomida desde que a lei entrou em vigor.

Foi relevante que as próprias pessoas com a síndrome se identificassem como vítimas e procurassem junto ao INSS a concessão do benefício da pensão vitalícia, bem como outros direitos criados posteriormente. As lutas mais recentes, em especial, conferem tonicidade ao reconhecimento observado a partir das reflexões de Axel Honneth (2003). As associações também agiram na luta contra o preconceito, dentro da própria esfera de convívio, bem como na sua própria articulação em prol de direitos.

Conforme Luis Otávio C. Falcão, que pertence à primeira geração da síndrome,

A luta nunca acaba, sempre vai ter alguma coisa que a gente vai ter que fazer, por direitos, por acessibilidade, sempre tem alguma coisa que a Associação não pode deixar passar. Então, quando a gente enxerga alguma coisa e vê que está errado [...] a briga tem que continuar. (MAXIMINO; TABOADA, 2012).

Essa visão é reforçada pelos escritos da ativista da causa da deficiência, Rosângela Berman Bieler (2003). As palavras da autora permitem refletir sobre como

O processo de se alcançar empoderamento e plena participação como cidadãos é longo e constante. Obriga-nos a forjar a nossa história, pessoal e coletiva, numa base diária. De fato, a participação plena somente pode ser verdadeiramente atingida dentro de uma sociedade inclusiva, na qual cada um de nós e todos nós sejamos considerados parte integral do todo, da comunidade que, por sua vez, é responsabilidade do conjunto de seus membros (BIELER apud VIVARTA, 2003, p. 31).

A nova articulação da associação, face ao contexto de inflação em descontrole, fica evidente nas palavras de Claudia Marques Maximino:

práticas neoliberais tornaram-se "[...] absolutamente contrári[as] ao fortalecimento da incipiente cidadania social conquistada com a redemocratização do país e consignada na Carta Magna”. (PEREIRA, 2010, p. 16). 
Quando eu comecei a ir atrás, aí saiu a pensão... aí eu me formei e não estava recebendo a pensão ainda e também não conseguia trabalho, aí acabei pensando: “Bom... vou correr atrás!" Juntei algumas pessoas [da primeira geração da talidomida] e começamos a procurar prefeitura, estado, o Covas... aí nos responderam: "Para vocês obterem alguma coisa... vocês têm que ser uma Associação". Foi nesse momento que fundei a Associação. Mas na verdade a gente só queria o aumento... então montamos a Associação... e aí a coisa engrenou... mas foi uma vitória... porque quando eu vi lá... que o [ex-presidente] Figueiredo assinou, eu fiquei super contente... [...] só que depois a gente demorou muito para receber... (informação verbal). 9

Ao rememorar essas perdas nos valores da pensão criada a partir da Lei n. 7.070/82, Maximino afirma:

Lógico que aquela primeira pensão foi boa, mas quando ela chegou já quase não existia... Também, porque demorou muito a ser paga [...]. Então, tirando o dinheiro que eu apliquei [...], eu lembro que dava para comprar um carro, que na época era o Monza, que as pessoas com deficiência faziam as adaptações para poder dirigir... Então, na verdade, [a pensão] foi positiva para as pessoas com a síndrome... Contudo, fomos perdendo no decorrer das décadas de 1980 e 1990, e [a pensão tornou-se o valor equivalente] a um ou dois, três litros de leite... (informação verbal).

A depoente lembra que a implementação da pensão não foi automática em relação à vigência da lei, e revela que muitos meses se passaram até que ela começasse a receber regularmente o valor referente ao benefício. Nesse ínterim, as famílias continuavam como únicas responsáveis pelos cuidados pessoais, médicos e de próteses/órteses.

Quando eu era pequena, minha mãe tinha que trocar as próteses todos os anos, pelo meu crescimento. As minhas pernas custavam o preço de um carro... a minha mãe fazia financiamento, fazia marmitex para fora, para poder comprar minhas pernas... [ela] fazia empréstimos no banco... Contudo, nunca deixaram me faltar nada... (informação verbal). ${ }^{10}$

Nesse sentido, alia-se o conteúdo dos dados à teoria do reconhecimento de Honneth (2003), o qual indica que algumas formas e manifestações de desrespeito e injustiça social motivam a luta por reconhecimento. Segundo o autor, essas lutas se caracterizam por situações em que "[...] experiências individuais de desrespeito [...] podem influir, como motivos diretores da ação, na

9 Entrevista concedida por Claudia Marques Maximino à autora, em 1 de julho de 2017.

${ }^{10}$ Entrevista concedida por Claudia Marques Maximino a Wanessa Veloso, em 2 de maio de 2014. 
exigência coletiva por relações ampliadas de reconhecimento." (HONNETH, 2003, p. 257). Isso fica evidente nas palavras de Maximino: "E ano após ano fomos conquistando leis, portarias, resoluções. Muitas ainda, apesar de sancionadas, não são cumpridas. O que nos faz continuar na luta." (informação verbal).

Flávio A. W. Scavasin, então vice-presidente da ABPST, indicou que, por ocasião da emergência da luta por reconhecimento e direitos, "Começaram a sair matérias sobre as vítimas da talidomida no Brasil, sobre as dificuldades das vítimas, e isso começou a pressionar, a nos ajudar a pressionar o governo com relação aos benefícios e às necessidades das vítimas." (MAXIMINO; TABOADA, 2012).

Como resultado da luta por reconhecimento desenvolvida a partir da ABPST, durante o governo Itamar Franco foi sancionada a Lei no 8.686/93, que orientava o reajuste da pensão vitalícia. A referida lei garantia, ainda, que o valor da pensão seria reajustado conforme os mesmos índices aplicados aos beneficiários do Benefício de Prestação Continuada ${ }^{11}$. Claudia Maximino analisa o impacto do sancionamento da lei:

O primeiro ganho foi o nosso reajuste, porque aí deu para respirar aliviada... consegui viver... tinha hora que eu trabalhava, tinha hora que eu não trabalhava... não só eu como todo mundo... Então, o maior ganho foi a Lei 8.686 de 1993, e a inclusão de próteses e órteses, porque a gente não tinha nada [...]. Foi um grande ganho no papel. E o valor da pensão, bem ou mal, está defasado, mas ainda continua nos sustentando [...]. (informação verbal). ${ }^{12}$

O estabelecimento da pensão vitalícia e mesmo da indenização não foram resolutivos ou até compensatórios das questões que permearam a vida das pessoas com a síndrome. Ou seja, a ação civil acordada não implicou automaticamente em conquistas de direitos sociais. As conquistas das entidades sociais, em especial a ABPST, permitem identificar um caráter comum entre elas:

\footnotetext{
${ }^{11}$ O Benefício da Prestação Continuada (BPC) éum benefício assistencial (o cidadão não precisa ser ou ter sido contribuinte do INSS para ter direito) que se caracteriza pelo repasse de um salário mínimo mensal para pessoas com mais de 65 anos e pessoas com deficiência de longo prazo, desde que fique comprovada que a renda mensal da família, para cada um dos membros do grupo, seja igual ou inferior a um quarto do salário mínimo. Santos indica que o BPC "[...] é um benefício da assistência social garantido na Constituição Federal de 1988, regulamentado pela Lei no 8.742, de 7 de dezembro de 1993 (Lei Orgânica de Assistência Social LOAS) e implantado de forma efetiva em 2 de janeiro de 1996." (2011, p. 788).

${ }^{12}$ Entrevista concedida por Claudia Marques Maximino à autora, em 1 de julho de 2017.
} 
todas refletem reconhecimento jurídico, via produção de leis e resoluções. Fica evidente que a mobilização foi fator determinante para as conquistas, pois todas foram iniciativas dos referidos movimentos. A coletividade representada pela ABPST foi formada e conduzida pelas próprias pessoas com a deficiência por talidomida. Os indivíduos se reconhecem como sujeitos de direito e atribuem-se papéis na luta para que a sociedade os identifique dessa forma.

Entende-se que o reconhecimento jurídico conquistado durante a década de 1990 abriu caminho para que diferentes demandas tomassem forma através da ABPST. Além das já citadas, Maximino destaca, ainda, outras conquistas da entidade:

Claro que todas as outras: [como] a regularização da talidomida, para não nascerem mais vítimas; a $\mathrm{RDC}^{13}$, porque até então as outras eram insuficientes. $\mathrm{E}$ tudo isso é um processo tão demorado... que já podia ter sido feito... bem quando nós começamos a procurar o Ministério Público passaram-se anos e anos e anos e a justiça não faz e acaba empurrando para o Governo mesmo, e o Governo é moroso, não é? Então de 1994 para a gente conseguir efetivamente a criminalização foi [apenas] em 2011... (informação verbal). ${ }^{14}$

Ademais, a Medida Provisória $\mathrm{n}^{0}$ 2.129/2001, que incide sobre a necessidade de valor financeiro referente ao pagamento para auxílio de um cuidador, desde que beneficiário da pensão e “[...] maior de 35 anos, que necessite de assistência permanente de outra pessoa e que tenha recebido pontuação superior ou igual a seis, [...] fará jus a um adicional de $25 \%$ sobre o valor deste benefício." (BRASIL, 2001).

Uma das conquistas mais recentes é a legislação em vigor sobre a indenização por danos morais às pessoas com a síndrome, a Lei $n^{0} 12.190$, de 2010:

Art. $1^{\mathrm{o}}$ É concedida indenização por dano moral às pessoas com deficiência física decorrente do uso da talidomida, que consistirá no pagamento de valor único igual a $\mathrm{R} \$ 50.000,00$ (cinquenta mil reais), multiplicado pelo número dos pontos indicadores da natureza e do grau da dependência resultante da deformidade física ( $\left(1^{\circ}\right.$ do art. $1^{\circ}$ da Lei $n^{\circ} 7.070$, de 20 de dezembro de 1982). (BRASIL, 2010).

${ }^{13}$ A depoente confere destaque à Resolução da Diretoria Colegiada (RDC) $n^{0} 11$, de 22 de março de 2011, publicada pela ANVISA, que apresentava a regulamentação técnica para controle da talidomida.

$14 \quad$ Entrevista concedida por Claudia Marques Maximino à autora, em 28 de junho de 2017. 
A lei que estipulou a reparação por dano moral beneficiou cerca de 650 pessoas, "[...] com um gasto estimado pela União de $\mathrm{R} \$ 34,5$ milhões." (BARROSO; FROTA, 2010, p. 101). Na análise de juristas brasileiros, há avanços e limitações nessa lei. Barroso e Frota (2010) avaliam que, “[...] apesar de algumas insuficiências [...]", a lei “[...] valoriza o caso concreto e a sua reparação, voltada que está para a cidadania material em razão da concretização da justiça social”. (p. 107). Por outro lado, os mesmos autores enunciam sua involução:

\begin{abstract}
Ressalte-se, contudo, que o art. $4^{\circ}$ da Lei 12.190/2010 preceitua que "as despesas decorrentes do disposto nesta Lei correrão à conta de dotações próprias do orçamento da União", a afastar a citada responsabilidade solidária, o que constitui um enorme equívoco, pois assume para si o Estado a total responsabilidade pelos danos decorrentes do uso da talidomida, quando se sabe que os laboratórios fabricantes do remédio contribuíram decisivamente para a consecução dos resultados danosos, porquanto em uma busca cada vez mais recrudescente pelo lucro (BARROSO; FROTA, 2010, p. 106).
\end{abstract}

Mesmo com os ganhos, salienta-se ainda a morosidade com que o Governo implementou o pagamento referente à indenização:

A própria indenização de danos morais foi sancionada no final de 2010, mas eu só recebi em 2012 [...], porque quando foi sancionada a Lei tiveram que fazer o decreto para regulamentar, somente então buscar o dinheiro no Orçamento, isso demorou mais de um ano também (informação verbal). ${ }^{15}$

O reconhecimento aqui analisado, compreendido como relacional, que emana do processo de luta dos sujeitos, passa por um dispositivo político relacionado à tomada de consciência sobre a sua condição (pessoa com tipo de deficiência específica, causada em um determinado momento da história, em decorrência de um medicamento), bem como a identificação das demandas, a formação da associação.

A mobilização, a formação das estratégias de ação, os contatos para ampliar a rede de associados foram parte do processo de luta por reconhecimento, que não se completou totalmente, pois tanto a síndrome da talidomida como os acontecimentos decorrentes dessa história não são de amplo conhecimento e, consequentemente, reconhecimento social. Entende-se que, ao ser acolhida como demanda pelos agentes políticos e quando transformada em legislação e direito ela é capaz de ampliar o nível do reconhecimento.

${ }^{15}$ Entrevista concedida por Claudia Marques Maximino à autora, em 28 de junho de 2017. 
Para o modelo social da deficiência, as pessoas com deficiência devem falar por si mesmas, destacando sua autonomia e independência. De acordo com Anahi G. Mello, isso significa que "[...] a autonomia (controle sobre o próprio corpo e sobre o ambiente mais próximo) e a independência (faculdade de decidir por si mesma) são os dois lados da mesma moeda" (MELLO, p. 2010, p. 6). No caso da talidomida, vale lembrar que toda a história desenvolvida até o trâmite que deu origem ao pagamento da pensão vitalícia obliterou o próprio sujeito com a síndrome, de forma a evidenciar o reconhecimento em etapas destacado por Honneth (2003). Por diversas vezes, em momentos diferentes, foi necessário que os sujeitos envolvidos se manifestassem para reivindicar direitos junto ao Estado e à sociedade.

\section{O Projeto de Lei do Senado (PLS) 504/15: uma nova etapa de luta}

A aprovação na Comissão de Direitos Humanos e Participação Legislativa (CDHPL), em que se votou a ampliação da pensão indenizatória paga pela União às pessoas com síndrome da talidomida no Brasil, quando devidamente comprovada por laudos médico-periciais é alvo da parte final deste artigo. A matéria contida no Projeto de Lei do Senado (PLS) 504/15 foi aprovada em 22 de março de 2017. No PLS votado na Comissão, previa-se a alteração na Lei $\mathrm{n}^{0}$ 8.686/93, requisitando o aumento de valor de referência: $\mathrm{R} \$ 1.000,00 . \mathrm{Na}$ primeira votação, a Comissão de Constituição e Justiça (CCJ) do Senado aprovou o texto, em 2 de março de 2016. Somente um ano depois é que o documento passou da CDHPL do Senado para a Câmara.

O PLS 504/2015 levou em conta aspectos que não foram mencionados ou sequer pensados no contexto de produção da Lei n. 7.070/82, quais sejam, o envelhecimento e problemas de saúde e outras deficiências causadas em decorrência das implicações físicas da síndrome. Além disso, emergiu a necessidade de novos cuidadores, uma vez que os pais, que durante muitos anos fizeram esse papel, já faleceram. Estes acontecimentos permitem reafirmar que os episódios ligados à temática são inconclusos e só voltam à cena pública em determinados momentos quando pessoas os levam a debate. Contudo, a luta dos movimentos é contínua, ainda que não entre na agenda midiática ou na pauta política com grande frequência. 
Considera-se que a participação na esfera política, via organização de um movimento social, bem como elaboração de estratégias de reivindicação de direitos - como ocupar espaços de luta no parlamento, acompanhar as votações e discussões sobre o projeto - pelos próprios sujeitos atingidos com a síndrome, representa grande ganho na manifestação de cidadania e na consequente conquista de direitos. A tônica do discurso deixava de incidir sobre o direito à igualdade, e passou a ser sobre o direito à diferença e direito à diversidade, todos esses respaldados pela noção de reconhecimento - da deficiência, dos direitos próprios a essa condição e das necessidades decorrentes das complicações da própria deficiência e do envelhecimento. A inexistência de políticas para as pessoas com deficiência, no período e, a ausência de diálogo entre os representantes do Estado e o movimento social das pessoas com a síndrome são entendidas como fatores de conflito e desrespeito, que motivaram a luta em busca da ampliação do valor do benefício.

Claudia Maximino, presente na sessão, concluiu seu discurso na ocasião, expressando que a luta não findava naquele evento: "Obrigada a todos os assessores que compraram a nossa briga. [...] e vamos continuar na luta, porque agora temos o calvário da Câmara [...]." (SOUSA, 2017). A fala da principal criadora da ABPST sintetizou a trajetória de luta e expressou a gratidão pela conquista momentânea, que ainda não era definidora da situação de aumento da pensão, referindo-se ao trâmite que foi concluído no mês de dezembro de 2017. O momento final desta luta ocorreu mais tarde, depois de aprovação na Câmara dos Deputados, quando foi sancionada pelo presidente Michel Temer a Lei $\mathrm{n}$. 13.638/2018, que alterou o valor mínimo da pensão vitalícia de $\mathrm{R} \$ 359,63$ para $\mathrm{R} \$ 1.000,00$, que entrou em vigência a partir de 2019.

\section{Considerações Finais}

Entende-se, pelos acontecimentos ligados à talidomida, que os veículos de comunicação impressa analisados tiveram um papel multifacetado, denunciando os eventos ligados à talidomida, expondo os possíveis responsáveis e abrindo espaço para notícias sobre a primeira associação; contudo, entende-se que também autuou como reprodutor de modelos dominantes. Eles contribuíram de formas diversas, ao longo dos anos, para a preservação do modelo biomédico 
da deficiência, principalmente ao deixar de estabelecer diálogo com as pessoas com a síndrome, para que as próprias veiculassem suas narrativas sobre suas experiências, conquistas e dores.

A criação da ABVT foi o primeiro passo na luta por direitos para as pessoas com deficiência. A Associação, fundada pela mãe de uma das crianças com a deficiência congênita por talidomida, ampliou a visibilidade sobre o tema com o apoio da mídia impressa e conseguiu contatar vários pais na mesma situação. O papel das associações das duas, cada uma em um contexto específico, foi determinante para que a sociedade conhecesse a síndrome da talidomida e para que o poder público criasse políticas públicas - de assistência, direitos e a própria regulamentação do medicamento, de forma a evitar novos casos de iatrogenia medicamentosa por talidomida, considerando que o fármaco ainda é produzido no país atualmente.

A luta por direitos dos atingidos pela talidomida no Brasil segue inconclusa: iniciada através da formação da ABVT para ingresso da ação judicial 5.678/76, culminou na Lei n. 7.070/82, a primeira que beneficiou as pessoas com a síndrome e que, com o tempo, se tornou insuficiente. Essa lei não definiu ou encerrou o papel do Estado em relação ao amparo às pessoas com a síndrome, como se pensava inicialmente. $\mathrm{O}$ contexto posterior à sua criação originou novas demandas e impulsionou novas frentes de luta por direitos, ou mesmo para a ampliação dos já existentes.

Também se verificou que o resultado veio tardiamente, muitos anos depois do nascimento das crianças. $\mathrm{O}$ acordo desenvolvido entre as partes não resultou em responsabilização dos laboratórios e estes acabaram comprometendo-se em pagar indenizações irrisórias. O processo judicial partiu do pressuposto que os acusados eram considerados responsáveis diretos, em que pese o ordenamento jurídico em vigência naquele contexto. Primava-se pela urgência do resultado, levando em conta a total falta de assistência aos atingidos pelo medicamento.

Evidencia-se, também, a dificuldade encontrada pelos demandantes em comprovar a conexão entre a deficiência e os produtos à base de talidomida, por ausência de registros sobre o consumo, como a prescrição médica. $O$ fato de boa parte da história do fármaco e do processo ter transcorrido em meio a um 
ambiente ditatorial não favoreceu a luta, muito menos os resultados obtidos. Considera-se que, tanto para o contexto imediatamente posterior aos danos causados pela talidomida, como para as décadas subsequentes, é válida a premissa de que o Estado e o modelo econômico impediram o avanço de políticas sociais em termos de direitos e cidadania social para as pessoas com deficiência no Brasil.

Entende-se, a partir da análise das fontes históricas e do levantamento bibliográfico, que a luta por reconhecimento desenvolvida por familiares e ativistas com o intuito de pressionar o poder público para visibilidade da causa é constante na agenda pública brasileira, com a articulação de movimentos sociais e a alteração de paradigmas - igualdade, dignidade e respeito às diferenças. Porém, mesmo com uma discussão bastante avançada em termos de Direitos Humanos, a deficiência não adquiriu centralidade suficiente para que atenda às necessidades das pessoas com deficiência e suas famílias. Destaca-se a inexistência do modelo social para quase todo o percurso histórico da talidomida no Brasil, por conta de uma conjuntura histórica e sociopolítica que excluía não apenas as pessoas com deficiência da proteção social como também a grande maioria da população.

Foram as próprias famílias que deram início à luta por reconhecimento, por reparação e por justiça compensatória. A identificação e o reconhecimento dos direitos dizem respeito não só a uma autoconsciência em relação às demandas, às próprias potencialidades e à luta, mas também o reconhecimento provindo de elementos externos ao cotidiano de vida dos atingidos pela talidomida, ou seja, o Estado e a sociedade.

No arco temporal pesquisado, as conquistas do período, embora limitadas pelo contexto sociopolítico e econômico, são inegáveis: partiu-se de uma realidade de total ausência de direitos e, por isso, invisibilidade social, para a instauração do Estatuto da Pessoa com Deficiência (2016). No entanto, o que se empreendeu nesta pesquisa foi a ampliação da evidência sobre a história da síndrome da talidomida no Brasil, bem como acerca determinados aspectos das conquistas alcançadas pelos sujeitos atingidos. Nesse sentido, há que reconhecer uma progressão de conquistas em termos de políticas sociais durante o recorte cronológico sobre o qual este artigo discorreu. 
Atualmente, mais de mil pessoas recebem a pensão indenizatória por ter síndrome da talidomida no Brasil. Contudo, acredita-se que o número de pessoas com deficiências em decorrência da síndrome pode ser divergente, justamente pela ausência de controle do Estado acerca dos dados sobre a talidomida.

\section{Referências}

ABBERLEY, Paul. El concepto de opresión y el desarrollo de una teoría social de la discapacidad. In: BARTON, L. (Org.). Superar las barreras de la discapacidad. Madrid: Ediciones Morata, S. L., 2008. p. 34-50.

ABPST. Home. Associação Brasileira de Portadores da Síndrome da Talidomida. Disponível em: <http://www.talidomida.org.br>. Acesso em: 02 set. 2018.

ASSOCIAÇÃO Brasileira das Vítimas da Talidomida. Disponível em: $<$ https://abvt.wordpress.com/abvt/> Acesso em: 19 jan. 2019.

BAHIA, Benedito Juarez. História, jornal e técnica: história da imprensa brasileira, vol. 1. Rio de Janeiro: Mauad X, 2009.

BARDIN, Laurence. Análise de conteúdo. São Paulo: Edições 70, 2011.

BARNES, Colin; OLIVER, Mike; BARTON, Len. Disability Studies Today. Cambridge: Polity Press, 2002.

BARROSO, Lucas Abreu; FROTA, Pablo Malheiros da Cunha. A obrigação de reparar por danos resultantes da liberação do fornecimento e da comercialização de medicamentos. Revista Trimestral de Direito Civil, v. 43, p. 99-114, 2010.

BIELER, Rosângela Berman. Inclusão e cooperação universal. In: VIVARTA, Veet. (Coord.). Mídia e deficiência. Brasília: Andi/Fundação Banco do Brasil, 2003. p. 31-33. Disponível em:

<http://www.andi.org.br/sites/default/files/Midia_e_deficiencia.pdf >. Acesso em: 02 set. 2018.

BONFIM, Symone Maria Machado. A luta por reconhecimento das pessoas com deficiência: aspectos teóricos, históricos e legislativos. 2009, 214 f. Dissertação (Mestrado) - Instituto Universitário de Pesquisas do Rio de Janeiro, Rio de Janeiro, 2010.

BRASIL. Ministério da Saúde. Secretaria de Vigilância em Saúde. Talidomida: orientação para uso controlado. Brasília: Ministério da Saúde, 2014.

. Poder Judiciário da União. Justiça Federal de Primeira Instância. Seção Judiciária do Estado do Rio Grande do Sul. Processo da 5.678/76. Rio Grande do Sul, 1983.

CAMPOS, André Luiz Vieira de; NASCIMENTO, Dilene Raimundo do, MARANHÃO, Eduardo. A história da poliomielite no Brasil e seu controle por imunização. História, Ciências, Saúde - Manguinhos. v. 10, suplemento 2, 
2003. p. 573-600. Disponível em: < https://www.nescon.medicina.ufmg.br/biblioteca/imagem/o936.pdf > . Acesso em: 15 mar. 2017.

DE CARLI, Ruvana. Deficiente versus pessoa portadora de deficiência: uma análise discursiva dos jornais Zero Hora e Correio do Povo. 2003, $134 \mathrm{f}$. Dissertação (Mestrado em Comunicação e Informação) - Faculdade de Biblioteconomia e Comunicação, Universidade Federal do Rio Grande do Sul, Porto Alegre, 2003.

DINIZ, Débora. O que é deficiência. São Paulo: Editora Brasiliense, 2007. FOUCAULT, Michel. Os anormais. São Paulo: Martins Fontes, 2001. GOFFMAN, Erving. Representação do eu na vida cotidiana. Petrópolis: Vozes, 1989.

GOHN, Maria da Glória. Movimentos sociais na contemporaneidade. Revista Brasileira de Educação, Rio de Janeiro, v. 16, n. 47, p. 333-361, ago. 2011. Disponível em:

<http://www.scielo.br/scielo.php?script=sci_arttext\&pid=S141324782011000200005\&lng=en\&nrm =iso > . Acesso em: 21 jul. 2019.

HONNETH, Axel. Luta por reconhecimento: a gramática moral dos conflitos sociais. Tradução de Luiz Repa. São Paulo: Editora 34, 2003.

KNIGHTLEY, Phillip. The Thalidomide Scandal: where we went wrong. In: PILGER, John. Tell me no lies: investigative journalism that changed the world. New York: Thunder's Mouth Press, 2005, p. 357-385.

LANNA JR, M. C. M. (Org.). História do Movimento Político das Pessoas com Deficiência no Brasil. Brasília: Secretaria de Direitos Humanos/Secretaria Nacional de Promoção dos Direitos da Pessoa com Deficiência, 2010.

LEANDRO, José Augusto; SANTOS, Francieli Lunelli. História da talidomida no Brasil a partir da mídia impressa (1959-1962). Revista Saúde Sociedade, São Paulo, v. 24, n. 3, p. 991-1005, 2015. Disponível em: <http://www.scielo.br/pdf/sausoc/v24n3/0104-1290-sausoc-24-0300991.pdf>. Acesso em: 02 set. 2017.

. Talidomida no Brasil: “à distinta classe médica”. In: JORNADA DE SOCIOLOGIA DA SAÚDE, 7., 2013, Curitiba. Anais... Curitiba: UFPR, 2013. Disponível em: <http://www.humanas.ufpr.br/portal/sociologiasaude/files/2013/12 /TALIDOMIDA-NO-BRASIL-IATROGENIA.pdf> . Acesso em: 13 jan. 2018.

MELLO, Anahi Guedes de. Perspectivas interdisciplinares dos estudos sobre deficiência para a sociologia da saúde e ecologia humana. In: SEMINÁRIO DE SOCIOLOGIA DA SAÚdE E ECOLOGIA HUMANA, 1., Florianópolis. Anais... Florianópolis: UFSC, set. 2010. Disponível em: <https://www.seminarioformprof.ufsc.br/files/2010/12/MELLO-AnahiGuedes-de2.pdf>. Acesso em: 10 mar. 2019. 
MUNHOZ, Dercio Garcia. Inflação brasileira: os ensinamentos desde a crise dos anos 30. Economia Contemporânea, n. 1, jan./jun. 1997.

OLIVER, Mike. Políticas sociales y discapacidad. Algunas consideraciones teóricas. In: BARTON, Len. (Org.) Superar las barreras de la

discapacidad. Madrid: Ediciones Morata, S. L., 2008. p. 19-33.

OLIVEIRA, Maria Auxiliadora; BERMUDEZ, Jorge Antônio Zepeda; SOUZA, Arthur Custódio Moreira de. Talidomida no Brasil: vigilância com responsabilidade compartilhada? Cadernos de Saúde Pública, Rio de Janeiro, v. 15, n. 1, p. 99-112, jan. 1999. Disponível em:

<http://www.funed.mg.gov.br/wp-content/uploads/2015/10/1999_-

Talidomida-no-brasil-vigilancia-com-responsabilidadecompartilhad a.pdf $>$. Acesso em: 02 set. 2019.

PEREIRA, Potyara Amazoneida. Política social do segundo pós-guerra: ascensão e declínio. Serviço Social e Saúde, Campinas, v. IX, n. 10, p. 1-21, dez. 2010. Disponível em:

<https://periodicos.sbu.unicamp.br/ojs/index.php/sss/article/view/8634888/ 2787>. Acesso em: 18 ago. 2019.

2009.

Política Social: temas e questões. 2. ed. São Paulo: Cortez,

SELAU, Bento; DAMIANI, Magda Floriana. Quando não se falava em inclusão: a história de vida do primeiro advogado cego formado no Brasil. Revista

Educação Especial, Santa Maria, v. 27, n. 49, p. 417-430, mai./ago. 2014. Disponível em: <http://cascavel.ufsm.br/revistas/ojs-

2.2.2/index.php/educacaoespecial/article/view/9633/pdf >. Acesso em: 30 jan. 2019.

SANTOS, Wederson Rufino dos. Os esquecidos: familismo e assistência pública na inimputabilidade por doença e deficiência mental no Brasil. 2014, 280 f. Tese (Doutorado em Sociologia) - Instituto de Ciências Sociais, Universidade de Brasília (UnB), Brasília, 2015. Disponível em: <http://repositorio.unb.br/bitstream/10482/17940/1/2014_Wederson RufinoSantos.pdf>. Acesso em: 03 set. 2019.

SOUSA, Regina. Comissão de Direitos Humanos e Legislação

Participativa. Senado Multimídia, 22 mar. 2017. Disponível em: <https://www12.senado.leg.br/multimidia/ evento/71419>. Acesso em: 12 mai. 2019.

TÁ FALTANDO ALGUMA COISA. Associação Brasileira dos Portadores da Síndrome da Talidomida (ABPST). São Paulo: Produtora, 2012. Duração 75 min. Disponível em: <https://www.youtube.com/watch?v=n8Dh4fYqtUU\&t=339s $>$. Acesso em: 12 fev. de 2016.

\section{Jornais e revistas consultados}

DIÁRIO CARIOCA, 20 set. 1965, p. 1

DIÁRIO DE NOTÍCIAS, 21 ago. 1973, p. 6 
Revista Brasileira de História \& Ciências Sociais - RBHCS

Vol. $13 \mathrm{~N}^{\circ}$ 25, Edição Especial de 2021

DIÁRIO DE NOTÍCIAS, 29 ago. 1973, p. 2; 6.

DIÁRIO DE NOTÍCIAS, 3 out. 1973

DIÁRIO DO PARANÁ, 12 jun. 1979, p. 4

DIÁRIO DO PARANÁ, 16 out. 1977, p. 2

DIÁRIO DO PARANÁ, 2 ago. 1978, p. 4

JORNAL DO DIA, 3 jan. 1963, p. 3

O CRUZEIRO, jan. 1975, p. 12

ÚLTIMA HORA, 15 nov. 1965, p. 5

ÚLTIMA HORA, 17 fev. 1983, p. 10

ÚLTIMA HORA, 24 jan. 1963, p. 6 